Journal of Research in Interprofessional

Practice and

Education

Vol. 4.1

June 2014
Journal of Research in Interprofessional Practice and Education (JRIPE)

Vol. 4.1

(C) 2014

Corresponding author: Catherine Anne Worthington. Email: 'worthing@uvic.ca!'

\section{HIV and Rehabilitation Training Needs of Health Professionals in Canada: Results of a National Survey}

\author{
Catherine Anne Worthington, PhD; Kelly O'Brien, PhD; Ted Myers, PhD; \\ Stephanie Nixon, PhD; \& Rhonda Cockerill, PhD
}

\begin{abstract}
Background: People with HIV experience a range of health-related challenges that rehabilitation services are well-positioned to address. The purpose of this study was to explore professional knowledge and views about HIV rehabilitation among HIV specialists and rehabilitation professionals in Canada.

Methods and Findings: We conducted a nationwide cross-sectional postal survey with a random sample of rehabilitation professionals (physical therapists, occupational therapists, speech-language pathologists, and physiatrists $)(N=1058)$ and the known population of HIV specialists (physicians, nurses, social workers, pharmacists, psychologists, and dietitians) in Canada $(N=214)$. Two-thirds $(67 \%)$ of rehabilitation professionals disagreed that rehabilitation professionals possess adequate knowledge and skills to assess and treat people living with HIV. The majority of all respondent groups felt that rehabilitation professionals who work with people living with HIV require specialized HIV training. Approximately one-third (32\%) of rehabilitation professionals who had served people living with HIV stated they received some HIV training as part of their professional degree.

Conclusions: This was the first national survey to explore HIV specialist and rehabilitation professionals' knowledge and views about HIV rehabilitation. Findings indicate the need for interprofessional education, training, and mentorship of health professionals to address the gap between the needs of people living with HIV and rehabilitation services provision.
\end{abstract}

Keywords: HIV/AIDS; Rehabilitation; Survey; Interprofessional education

\section{Introduction}

In countries where mortality rates for HIV are declining as a result of antiretroviral therapies, HIV is increasingly perceived as a chronic illness [1,2]. As a result, a greater number of individuals may be living with a range of health-related challenges of HIV, its associated conditions, and adverse effects of antiretroviral treatment. Adults living long term with HIV may experience a range of impairments (problem at the level of the body part or function such as fatigue or weakness), activity limitations (difficulty with a task or action, such as walking) or social participation restrictions (difficulty engaging in a life situation, such as employment) [3]. A survey conducted in British Columbia, Canada, documented that $80 \%$ of those surveyed experienced at least one impairment, activity limitation, or participation restriction attributed to their HIV status within the last month [3]. This disablement is often episodic in nature, characterized by unpredictable periods of illness and wellness, which further impacts overall health and quality of life of people living 
2

HIV and

Rehabilitation

Training Needs

Worthington, O'Brien, Myers, Nixon, \& Cockerill

Journal of Research in Interprofessional Practice and Education

Vol. 4.1

June 2014 with HIV [4,5]. Additional factors, such as stigma, concurrent health conditions, and aging, add further complexity to the care and treatment of people living with HIV. Hence, the service needs of people living with HIV have become increasingly complex and require flexible delivery of HIV care across the continuum, beyond the medical monitoring of antiretroviral treatment [6].

Rehabilitation activities and services are well-positioned to address the healthrelated challenges of HIV using a broad approach to disability that promotes quality of life in physical, psychological, emotional, social, and community participation domains [7]. Rehabilitation is broadly defined as all services and activities that address or prevent impairments, activity limitations, or social participation restrictions experienced by an individual [6]. Providers of rehabilitation services may include rehabilitation professionals (e.g., occupational therapists, physical therapists, and speech-language pathologists) and other clinical or community-based providers (e.g., psychologists, pharmacists, social workers). However, few of those customarily considered to be the rehabilitation professions-including physical therapy (PT), occupational therapy (OT), and speech-language pathology (SLP)—work with people living with HIV [8].

In a recent Canadian survey, we found that $61 \%$ of participating rehabilitation professionals had never knowingly worked with a person living with HIV. Of these, 27\% were unwilling to work with this population and $46 \%$ were unsure whether they would work with this population [8]. In multivariate modelling, factors significantly associated with serving people living with HIV were higher reported HIV knowledge and receipt of specialty training or continuing education in HIV rehabilitation in the past five years [8]. In a parallel survey, we found that HIV specialists (a range of health professionals working predominantly with HIV patients) tended to refer their clients to community-based AIDS service organizations or social workers to address social participation restrictions, while fewer referred to rehabilitation professionals and other providers [9]. This gap in service provision may be attributed in part to a lack of knowledge among rehabilitation professionals and referring health professionals about the role for rehabilitation in the context of HIV, and also to perceptions among rehabilitation professionals that they lack the skills and training to adequately assess and treat people living with HIV.

Training and mentorship educational strategies could enhance the capacity of providers so they may become better equipped to address this gap in service provision [10-12]. However, little is known about the HIV training and mentorship needs of health providers in HIV and rehabilitation. A range of HIV educational curricula exist in Canada, but few programs specifically target the area of HIV rehabilitation, few provide interprofessional perspectives, and few programs have been formally evaluated [13]. In order to inform training and mentorship in the field, the purpose of this analysis was to explore the knowledge and professional views about HIV rehabilitation among HIV specialists and rehabilitation professionals in Canada. Specific objectives were: a) to describe levels of knowledge and training about rehabilitation in the context of HIV, and b) to describe views on HIV rehabilitation. 
3

HIV and Rehabilitation Training Needs

Worthington, O'Brien, Myers, Nixon, \& Cockerill
Journal of Research in Interprofessional Practice and Education

Vol. 4.1

June 2014

\section{Methods}

\section{Study design}

We conducted nationwide cross-sectional postal surveys on HIV and rehabilitation with a random sample of rehabilitation professionals (physical therapists, occupational therapists, speech-language pathologists, and physiatrists) and the known population of HIV specialists (physicians, nurses, social workers, pharmacists, psychologists, and dietitians) in Canada who had undertaken clinical work in the past year.

The study protocol was approved by the University of Toronto HIV Research Ethics Board. A national advisory committee, consisting of people living with HIV, rehabilitation professionals with experience in HIV, and representatives from regulatory bodies and HIV organizations, was consulted through all phases of the study.

\section{Survey instrument}

We used the HIV/AIDS Rehabilitation Conceptual Framework, developed in earlier phases of this work, to guide the questionnaire construction [6]. The International Classification of Functioning, Disability and Health (ICF) [14], was used in this framework to broadly define rehabilitation as all services and activities that address or prevent impairments, activity limitations, or social participation restrictions experienced by an individual [6].

The rehabilitation professionals' survey instrument included sections on: 1) current clinical rehabilitation practice and service provision issues, 2) types of patients served, 3) HIV knowledge and training, 4) views on the roles of health providers in HIV rehabilitation, and 5) HIV rehabilitation service delivery issues. The survey instrument for HIV specialists included parallel sections on 1) current HIV clinical and referral practices, 2) types of patients served, 3) HIV and rehabilitation knowledge and training, 4) views on the roles of health providers in HIV rehabilitation, and 5) HIV rehabilitation service delivery issues. The survey instruments were constructed, pre-tested, and refined with the national advisory committee. The final instruments were translated into French by a translator with expertise in HIV rehabilitation. The mailing procedure was pilot tested with five rehabilitation professionals and five HIV specialists.

\section{Target sample}

While the HIV/AIDS Rehabilitation Conceptual Framework identified multiple stakeholders who possess a role in rehabilitation for people living with HIV, we focused on the traditionally defined rehabilitation professionals, including occupational therapists (OTs), physiatrists, physical therapists (PTs), and speech-language pathologists (SLPs) who had practiced clinically within the past year and who may or may not have worked in the area of HIV, as well as the known population of HIV specialists, including dietitians, nurses, pharmacists, physicians, psychologists, and social workers in Canada [8,9]. 
4

HIV and Rehabilitation Training Needs

Worthington, O'Brien, Myers, Nixon, \& Cockerill
Journal of Research in Interprofessional Practice and Education

Vol. 4.1

June 2014

\section{Sampling frame}

For the rehabilitation professionals, we drew a random sample $(N=2105)$ from national rehabilitation professional association lists (Canadian Physiotherapy Association, Canadian Association of Occupational Therapists, and Canadian Association of SpeechLanguage Pathology and Audiology). In order to obtain the most complete and representative sampling frame possible, these lists were cross-checked and supplemented with available provincial/territorial regulatory body lists. This cross-check increased the total rehabilitation pool from which to draw the random sample by over 30\% (37\% for OTs, 24\% PTs, and 36\% SLPs). For physiatrists, we drew a random sample from a regulatory body list.

For the HIV specialists, we created a mailing list of all known HIV health professionals in the target groups practicing in Canada through HIV-specific associations or colleges that identified professionals based on HIV specialty. Given the relatively small total $(N=793)$, we surveyed the entire population rather than drawing a sample. We supplemented our sample using a snowball technique by inviting respondents to provide contact information for professional colleagues working in HIV care.

\section{Survey implementation}

We used the Dillman Tailored Design Method, a four-step mailing process, to implement the survey [15]. Mailing steps included 1) a notice letter mailed approximately 1 week prior to the survey package, 2) the survey package, including cover letter, questionnaire, refusal card, and a self-addressed prepaid return envelope, 3 ) a thank you/reminder postcard mailed 1-2 weeks after the survey package, and for those who did not respond, 4) a second survey package mailed 2-4 weeks after the first. Questionnaires were distributed in English to all provinces and territories, and French and English materials were mailed to Québec and New Brunswick.

\section{Analysis}

Questionnaire data were double entered for verification. For comparisons between professional groups, we focused our analysis on identical items included in both the HIV specialist and rehabilitation professional survey instruments.

Descriptive statistics were used to summarize results in areas of current practice and services provided, levels of knowledge, views on the roles of health service providers and emerging professional and service delivery issues, and demographic information. Due to differences in sample size, and to preserve confidentiality of respondents, for the purposes of this article we present information on HIV specialists, and where relevant, either information on all rehabilitation professionals, rehabilitation professionals who had not served people living with HIV (or were unsure), and/or rehabilitation professionals who had knowingly served people living with HIV. We chose to group rehabilitation professionals in two sub-categories where possible, based on our previous finding that they had different levels of knowledge and training. [8] 
HIV and Rehabilitation Training Needs

Worthington, O'Brien, Myers, Nixon, \& Cockerill

\section{Results}

\section{Response rates}

Of the 2105 rehabilitation professional surveys mailed, 99 (5\%) could not be delivered (returned to sender with no tracing possible). Of the 2006 remaining, 1492 (74\%) responses were received, of which $198(10 \%)$ respondents were ineligible to participate (no clinical practice within the past year), 236 (12\%) refused to participate, and 1058 (53\%) completed the survey (Figure 1).

Of the 793 HIV health professional surveys mailed, 62 (8\%) were undeliverable. Of the 731 remaining, we received $462(63 \%)$ responses: $134(18 \%)$ were ineligible to participate (no clinical practice within the past year), 114 (16\%) returned refusal cards, and $214(29 \%)$ completed the survey (36\% of the eligible respondents) (Figure 1).

\section{Figure 1:}

\section{Overview of survey responses for rehabilitation professionals and HIV specialists}

HIV Specialists

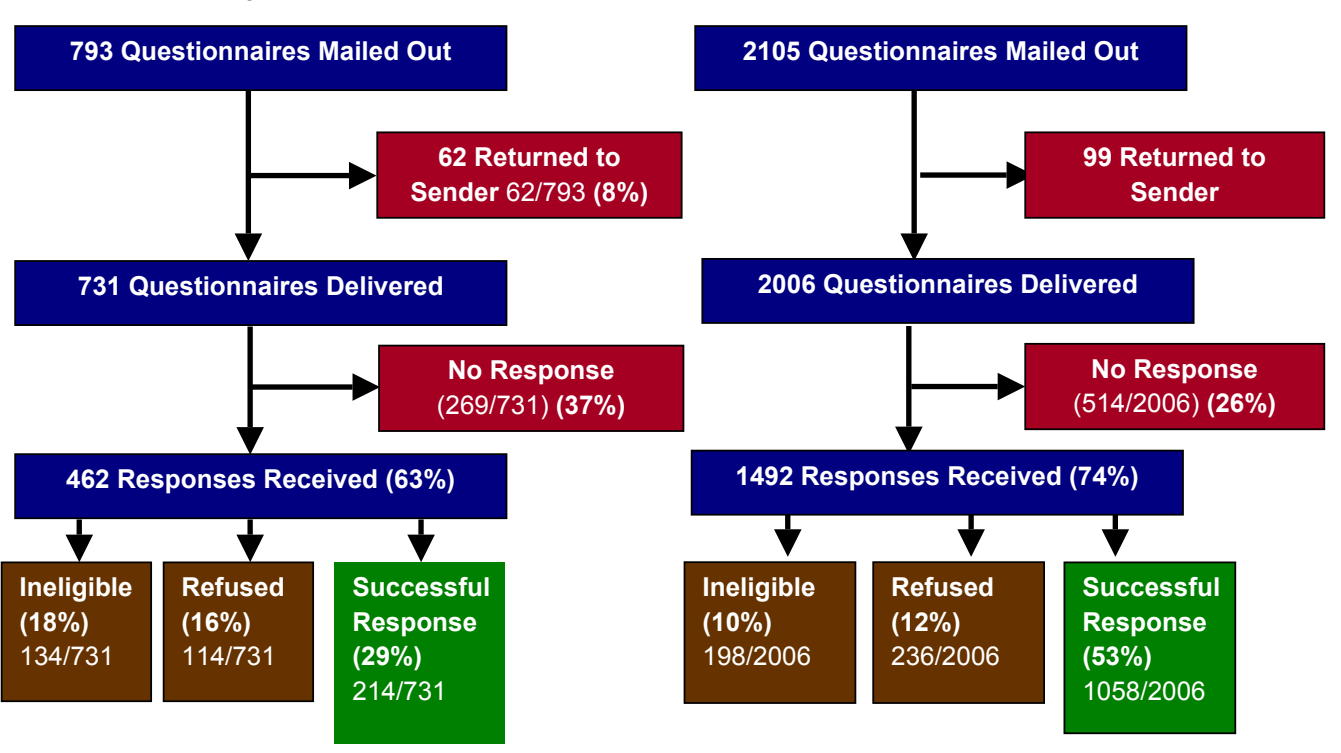

Notes: Ineligible $=$ Rehabilitation professionals and HIV specialists who did not meet the inclusion criteria. Those excluded were rehabilitation professionals who had not worked in a clinical setting or HIV specialists who had not worked in a clinical HIV setting in the previous 12 months. All surveys included preliminary screening questions on work in a clinical or clinical HIV setting in the previous year. Successful = Eligible health professionals who successfully completed and returned questionnaires. Refused = Eligible health professionals who refused participation by returning a refusal card. * percentages may not add to $100 \%$ due to rounding.

Journal of Research in Interprofessional Practice and Education

Vol. 4.1

June 2014

\section{Respondent characteristics and HIV practice characteristics}

Respondent characteristics for HIV specialists and rehabilitation professionals are displayed in Table 1. For the rehabilitation professional respondents, $47 \%$ were PTs, $41 \%$ were OTs, 9\% were SLPs, and 3\% were physiatrists. These response rates were roughly proportionate to the size of each profession surveyed. Rehabilitation profes- 
6

HIV and Rehabilitation Training Needs

Worthington, O'Brien, Myers, Nixon, \& Cockerill

Journal of Research in Interprofessional Practice and Education

Vol. 4.1

June 2014
Table 1:

\section{Description of respondents - HIV specialists} and rehabilitation professionals

\begin{tabular}{|c|c|c|}
\hline & \begin{tabular}{|l|} 
HIV specialists \\
$N$ (\% among HIV specialists). \\
$N=214^{*}$
\end{tabular} & $\begin{array}{l}\text { Rehabilitation professionals } \\
\text { (who had or not knowingly served } \\
\text { people living with HIV). } N=1058^{*}\end{array}$ \\
\hline $\begin{array}{l}\text { Profession** }^{*} \\
\text { Nurse } \\
\text { Physician } \\
\text { Social Worker } \\
\text { Pharmacist } \\
\text { Psychologist } \\
\text { Dietician } \\
\text { Occupational Therapist } \\
\text { Physical Therapist } \\
\text { Speech-Language Pathologist } \\
\text { Physiatrist }\end{array}$ & $\begin{array}{c}100(47 \%) \\
75(35 \%) \\
14(6 \%) \\
13(6 \%) \\
7(3 \%) \\
5(2 \%) \\
- \\
- \\
-\end{array}$ & $\begin{array}{l}- \\
- \\
- \\
- \\
- \\
432(41 \%) \\
500(47 \%) \\
96(9 \%) \\
30(3 \%)\end{array}$ \\
\hline $\begin{array}{l}\text { Gender } \\
\text { Female } \\
\text { Male }\end{array}$ & $\begin{array}{r}109(65 \%) \\
58(35 \%)\end{array}$ & $\begin{array}{l}913(88 \%) \\
126(12 \%)\end{array}$ \\
\hline $\begin{array}{l}\text { Age } \\
\quad<25 \text { years } \\
25-35 \text { years } \\
36-50 \text { years } \\
>50 \text { years }\end{array}$ & $\begin{array}{l}0(0 \%) \\
24(14 \%) \\
89(54 \%) \\
52(32 \%)\end{array}$ & $\begin{array}{r}10(<1 \%) \\
434(42 \%) \\
430(41 \%) \\
164(16 \%)\end{array}$ \\
\hline $\begin{array}{l}\text { Community Size } \\
\text { Metro }(>500,000) \\
\text { Urban }(100,000-500,000) \\
\text { Rural }(<100,000)\end{array}$ & $\begin{array}{r}128(60 \%) \\
64(30 \%) \\
20(9 \%)\end{array}$ & $\begin{array}{l}448(43 \%) \\
327(31 \%) \\
267(26 \%)\end{array}$ \\
\hline $\begin{array}{l}\text { Region } \wedge^{* *} \\
\text { Ontario } \\
\text { Alberta } \\
\text { British Columbia } \\
\text { Prairies (Saskatchewan and Manitoba) } \\
\text { Atlantic Canada (NS, NB, PEI, NFLD) } \\
\text { Québec } \\
\text { Northwest Territories, Yukon, Nunavut }\end{array}$ & $\begin{array}{l}78(36 \%) \\
17(8 \%) \\
39(18 \%) \\
18(8 \%) \\
15(7 \%) \\
43(20 \%) \\
4(2 \%)\end{array}$ & $\begin{array}{l}563(53 \%) \\
140(13 \%) \\
111(10 \%) \\
105(10 \%) \\
98(9 \%) \\
35(3 \%) \\
6(<1 \%)\end{array}$ \\
\hline Northern Region & $17(8 \%)$ & $80 \quad(8 \%)$ \\
\hline $\begin{array}{l}\text { Work Setting (categories not mutually } \\
\text { exclusive) } \\
\text { Client's Home (home care) } \\
\text { Hospital - inpatient } \\
\text { Hospital - outpatient } \\
\text { Private practice } \\
\text { HIV specialty clinic } \\
\text { AIDS service organization }\end{array}$ & $\begin{array}{r}0(0 \%) \\
89(42 \%) \\
108(50 \%) \\
20(9 \%) \\
98(46 \%) \\
20(9 \%)\end{array}$ & $\begin{array}{r}306(29 \%) \\
306(29 \%) \\
230(22 \%) \\
431(41 \%) \\
3(<1 \%) \\
2(<1 \%)\end{array}$ \\
\hline Years in Practice (mean) & $16(s d=10)$ & $14(s d=10)$ \\
\hline
\end{tabular}

Notes: ${ }^{*}$ Ns vary by question due to item non-response. $\wedge$ NB=New Brunswick, NS=Nova Scotia, PEl=Prince Edward Island, NFLD=Newfoundland. **Percentages may not add to $100 \%$ due to rounding. 


\section{JRIPE}

7

HIV and

Rehabilitation

Training Needs

Worthington, O'Brien, Myers, Nixon, \& Cockerill

sional respondents had practiced an average of 14 years, and were engaged in a combination of activities, including clinical care, research, education, administration, policy work, and health promotion. Of the rehabilitation professional respondents, $39 \%$ had knowingly served an HIV-positive client in the past year, and on average they served one client in the past month $(s d=3)$.

Of the HIV specialist respondents, just under half (47\%) were nurses, and approximately a third were physicians (35\%). Proportionate to the sampling frame, dietitians and physicians were under-represented in the sample, while the other four professions (nurses, social workers, pharmacists, psychologists) were over-represented. HIV specialist respondents had practiced an average of 16 years, and worked in a variety of hospital inpatient, outpatient, HIV specialty clinic, private practice, and AIDS service organization settings.

Practice characteristics for HIV specialists and rehabilitation professionals who reported they had knowingly served people living with HIV are displayed in Table 2.

Table 2:

\section{Description of practice characteristics - HIV specialists and rehabilitation professionals who served HIV clients}

\begin{tabular}{|c|c|c|}
\hline & $\begin{array}{l}\text { HIV Specialists } \\
N \text { (\% among HIV } \\
\text { specialists) } \\
N=214^{*}\end{array}$ & $\begin{array}{l}\text { Rehabilitation professionals } \\
\text { who had knowingly served } \\
\text { people living with HIV } \\
N=406 / 1042^{*}(39 \%) \\
N \text { (\% within rehabilitation } \\
\text { professionals who had served) }\end{array}$ \\
\hline Number of HIV Clients served in the last month (mean) & $54(s d=104)$ & $1(s d=3)$ \\
\hline $\begin{array}{l}\text { HIV clinical caseload activities in a typical week (frequently } \\
\text { or always) (categories not mutually exclusive) } \\
\text { Assessment } \\
\text { Treatment } \\
\text { Consultation } \\
\text { Health promotion }\end{array}$ & $\begin{array}{l}161(75 \%) \\
152(71 \%) \\
148(68 \%) \\
136(64 \%)\end{array}$ & $\begin{array}{r}106(53 \%) \\
104(51 \%) \\
95(47 \%) \\
78(39 \%)\end{array}$ \\
\hline $\begin{array}{l}\text { HIV client groups frequently or always served in clinical } \\
\text { practice (categories not mutually exclusive) } \\
\text { Men who have sex with men } \\
\text { People who use injection drugs } \\
\text { Women } \\
\text { People from countries where HIV is endemic } \\
\text { Aboriginal individuals } \\
\text { Youth } \\
\text { Children }\end{array}$ & $\begin{array}{r}162(78 \%) \\
127(61 \%) \\
121(58 \%) \\
75(36 \%) \\
70(34 \%) \\
26(12 \%) \\
12(6 \%)\end{array}$ & $\begin{array}{rr}21 & (12 \%) \\
20 & (11 \%) \\
17 & (10 \%) \\
7 & (4 \%) \\
13 & (8 \%) \\
4 & (2 \%) \\
5 & (3 \%)\end{array}$ \\
\hline $\begin{array}{l}\text { Link with community-based AIDS service organizations as } \\
\text { part of your HIV clinical practice? }\end{array}$ & $171(85 \%)$ & $32(16 \%)$ \\
\hline $\begin{array}{l}\text { Link with any providers in complementary and alternative } \\
\text { therapies or medicine as part of your HIV clinical practice? }\end{array}$ & $46(22 \%)$ & $18(9 \%)$ \\
\hline
\end{tabular}


8

HIV and Rehabilitation Training Needs

Worthington, O'Brien, Myers, Nixon, \& Cockerill

Journal of Research in Interprofessional Practice and Education

Vol. 4.1

June 2014
The practice contexts of HIV specialists and rehabilitation professionals are understandably different. For HIV specialists, there was wide variation in the average number of HIV clients seen in the past month $(N=54, s d=104)$, and more than half indicated they frequently or always engaged in a wide range of HIV clinical caseload activities in a typical week (e.g., assessment [75\%], health promotion [64\%], or treatment [71\%]) in terms of their HIV clinical caseload activities. By comparison, among the rehabilitation professionals who had served people living with HIV, approximately half or less indicated they engaged in assessment (53\%), treatment (51\%), consultation (47\%), or health promotion (39\%) activities with clients living with HIV in a typical week. In terms of client groups seen, there were also differences. For example, $64 \%$ of HIV specialists indicated they frequently or always served men who have sex with men, whereas only $12 \%$ of rehabilitation professionals indicated the same. Eighty-five percent of HIV specialists linked with community-based AIDS service organizations as part of their clinical practice, compared with only $16 \%$ of rehabilitation professionals who worked with HIV clients. Similarly, a higher percentage of HIV specialists referred their HIV clients to complementary and alternative therapy providers (22\%) compared with rehabilitation professionals (9\%).

\section{Level of knowledge and training}

\section{Knowledge}

As noted, in a previous analysis [8] we found that for rehabilitation professionals, HIV knowledge was positively associated with having knowingly served people living with HIV. For example, rehabilitation professional respondents who had not served people living with HIV rated themselves as "not at all knowledgeable" in areas of HIV-related policies (83\%), the episodic course of HIV infection (75\%), treatment medications for HIV (74\%), HIV pathogenesis (64\%), and HIV epidemiology (57\%). By contrast, a smaller percent of rehabilitation professionals who had served people living with HIV rated themselves as "not at all knowledgeable" in these same areas of HIV-related policies (73\%), treatment medications for HIV (64\%), the episodic course of HIV infection (58\%), HIV pathogenesis (51\%), and HIV epidemiology (44\%). As expected, the majority of HIV specialists rated themselves as "very knowledgeable" in areas of HIV transmission (95\%), HIV prevention (95\%), HIV diagnosis (87\%), psychosocial aspects of HIV (68\%), and treatment medications for HIV (67\%). But, interestingly, only two-thirds or less rated themselves as very knowledgeable about the episodic course of HIV infection (66\%), HIV epidemiology (63\%), HIV-associated disability (58\%), and HIV pathogenesis (55\%), and only $37 \%$ rated themselves as very knowledgeable about HIV-related policies.

\section{Training}

We were interested in the types of training health professionals had experienced. For rehabilitation professionals who had served people living with HIV, $32 \%$ of 
9

HIV and Rehabilitation Training Needs

Worthington, O'Brien, Myers, Nixon, \& Cockerill

Journal of Research in Interprofessional Practice and Education

Vol. 4.1

June 2014 respondents stated they received training in HIV as part of their professional health degree, with a mean total number of hours of education in HIV of 15 (range 0-435 hours). For rehabilitation professionals who had not served people living with HIV, only $24 \%$ stated they received training in HIV as part of their professional health degree, with a mean total number of hours of education in HIV of 8 (range 0-40 hours). Of those rehabilitation professionals who received training, the most common types of HIV training were HIV lectures or guest speakers (68\%), HIV educational materials (e.g., literature, videos, manuals) (65\%), and case studies related to HIV (54\%). Few of the rehabilitation professionals who received training as part of their professional degree received HIV clinical placements or internships (12\%) and mentorship or shadowing opportunities with health professionals in the area of HIV (9\%).

HIV specialists were asked whether they had exposure to training on rehabilitation. Fourteen percent $(N=29)$ of HIV specialist respondents indicated they received training in rehabilitation as it relates to HIV as part of their professional health degree, with a mean total number of hours of HIV rehabilitation education of 65 (range 0-300 hours). This ranged from a mean of 12 hours (dietitians) to 300 hours (social workers). For the small number of HIV specialists who had received rehabilitation training as part of their professional degree, the most common types of rehabilitation training received were rehabilitation and HIV lectures and guest speakers (89\%), rehabilitation and HIV training opportunities (e.g., workshops, courses, conferences) (78\%), rehabilitation and HIV educational materials (e.g., literature, videos, manuals) (74\%), and case studies related to rehabilitation in the context of HIV (74\%). Compared with rehabilitation professionals, a larger percentage of HIV specialists who received training as part of their professional degree reported having received mentorship or shadowing opportunities with health professionals in HIV rehabilitation (59\%) and clinical placements or internships (52\%).

Nineteen percent of rehabilitation professional respondents, who had served people living with HIV, reported they had participated in specialty training or continuing education beyond that received in their health degree education in the area of rehabilitation related to HIV in the past five years, whereas only $6 \%$ of rehabilitation professionals, who had not served people living with HIV, received post-degree specialty training or education. Similar to the training within their professional degrees, types of specialty training and education received post-degree was in the form of HIV educational materials (e.g., literature, videos, manuals) (85\%) or HIV lectures and guest speakers (68\%), and very few had experienced mentorship or shadowing programs with other professionals (10\%) or HIV clinical placements or internships (8\%).

By contrast, 59\% of HIV specialist respondents reported they had received specialty training or continuing education beyond their degree in the area of rehabilitation related to HIV. However, given our broad definition of HIV rehabilitation, respondents may have been including a wide range of training/education activities. Similar to the rehabilitation professionals, the form of training tended to include HIV lectures and guest speakers (94\%) and HIV educational materials (e.g., litera- 
10

HIV and Rehabilitation Training Needs

Worthington, O'Brien, Myers, Nixon, \& Cockerill

Journal of Research in Interprofessional Practice and Education

Vol. 4.1

June 2014 ture, videos, manuals) (89\%), whereas fewer took part in mentorship or shadowing programs (26\%) and clinical placements or internships (17\%).

\section{Views on HIV rehabilitation}

Both respondent groups were asked about their views on their professions and HIV rehabilitation. As might be expected, a large percentage (75\%) of HIV specialist respondents felt that their professions were "very important" in the rehabilitation of people living with HIV. However, of the rehabilitation professionals who reported they had served a person living with HIV, only approximately half (53\%) indicated their profession was "very important" in the rehabilitation of people living with HIV; and of rehabilitation professionals who did not serve HIV clients, only $41 \%$ felt their profession was "very important" in the rehabilitation of people living with HIV. When asked how they perceived the role of other health providers in HIV rehabilitation, over $80 \%$ of rehabilitation professional respondents (both those who did and did not serve people living with HIV) indicated that general practitioners, infectious disease specialists, nurses, pharmacists, social workers, dietitians, and community-based AIDS service organizations (in areas of return to work, vocational rehabilitation, housing, and coping support) are "very important" in serving people living with HIV. In addition to these health providers, over 80\% of HIV specialist respondents also indicated that psychiatrists are "very important" in HIV rehabilitation.

Table 3 displays professional views about the role of rehabilitation in the context of HIV. Forty-five percent (45\%) of HIV specialist respondents agreed or strongly agreed that rehabilitation professionals possessed adequate knowledge and skills to work with people living with HIV, whereas the majority of rehabilitation professional respondents disagreed with this statement $(62 \%$ of those who had knowingly served a person living with HIV, and 70\% of those who had not knowingly served a person living with HIV). The majority of all groups of respondents agreed with the statement that rehabilitation professionals who work with people living with HIV require specialized training (94\% of HIV specialists, 89\% of rehabilitation professionals who had knowingly served people living with HIV, and $92 \%$ of rehabilitation professionals who had not knowingly served people living with HIV). The majority of rehabilitation professionals who had served people living with HIV (67\%) disagreed that serving people living with HIV is more demanding than serving clients with other chronic illnesses or conditions, whereas HIV specialist respondents appeared more divided on this statement, with $47 \%$ agreeing or strongly agreeing, and $45 \%$ disagreeing or strongly disagreeing. For rehabilitation professionals who had not served people living with HIV, 44\% disagreed or strongly disagreed with the statement, but another $42 \%$ said "don't know." Also of note, 58\% of HIV specialist respondents felt that rehabilitation for people living with HIV should be a larger priority, whereas $38 \%$ and $39 \%$ of rehabilitation professionals who had or had not knowingly served HIV clients, respectively, had this opinion. 
11

HIV and Rehabilitation Training Needs

Worthington, O'Brien, Myers, Nixon, \& Cockerill
Journal of Research in Interprofessional Practice and Education

Vol. 4.1

June 2014
Table 3:

\section{Views on HIV/AIDS rehabilitation}

\begin{tabular}{|c|c|c|c|}
\hline & $\begin{array}{l}\text { HIV specialists } \\
N \text { (\% among HIV } \\
\text { specialists) } \\
N=214^{*}\end{array}$ & $\begin{array}{l}\text { Rehabilitation professionals } \\
\text { who HAD knowingly served } \\
\text { people living with HIV. } \\
N=406 / 1042^{*}(39 \%) \text {. } \\
N \text { (\% within rehabilitation } \\
\text { professionals who had served) }\end{array}$ & $\begin{array}{l}\text { Rehabilitation professionals } \\
\text { who had NOT knowingly served } \\
\text { (or not sure) } \\
N=636 / 1042^{*}(61 \%) . N \text { (\% within } \\
\text { rehabilitation professionals who } \\
\text { had not knowingly served) }\end{array}$ \\
\hline \multicolumn{4}{|c|}{$\begin{array}{l}\text { Rehabilitation professionals currently possess adequate knowledge and skills to assess } \\
\text { and treat people living with HIV/AIDS*** }\end{array}$} \\
\hline $\begin{array}{l}\text { Strongly Agree } \\
\text { Agree } \\
\text { Disagree } \\
\text { Strongly Disagree } \\
\text { Don't Know }\end{array}$ & $\begin{array}{c}14(7 \%) \\
78(38 \%) \\
66(32 \%) \\
7(3 \%) \\
42(20 \%)\end{array}$ & $\begin{array}{r}6(1 \%) \\
99(25 \%) \\
213(53 \%) \\
36(9 \%) \\
49(12 \%)\end{array}$ & $\begin{array}{r}16(3 \%) \\
75(12 \%) \\
368(58 \%) \\
77(12 \%) \\
97(15 \%)\end{array}$ \\
\hline \multicolumn{4}{|c|}{$\begin{array}{l}\begin{array}{l}\text { Rehabilitation professionals who provide services for people living with HIV need specialized training } \\
\text { in the area of HIV/AIDS** }\end{array} \\
\end{array}$} \\
\hline $\begin{array}{l}\text { Strongly Agree } \\
\text { Agree } \\
\text { Disagree } \\
\text { Strongly Disagree } \\
\text { Don't Know }\end{array}$ & $\begin{array}{rr}114 & (55 \%) \\
81 & (39 \%) \\
6 & (3 \%) \\
1 & (1 \%) \\
5 & (2 \%)\end{array}$ & $\begin{array}{c}195(48 \%) \\
167(41 \%) \\
24(6 \%) \\
6(2 \%) \\
11(3 \%)\end{array}$ & $\begin{array}{rr}402 & (64 \%) \\
179 & (28 \%) \\
9 & (1 \%) \\
28 & (4 \%) \\
16 & (3 \%)\end{array}$ \\
\hline \multicolumn{4}{|c|}{ Working with people living with HIV/AIDS is similar to working with individuals with other chronic illnesses** } \\
\hline $\begin{array}{l}\text { Strongly Agree } \\
\text { Agree } \\
\text { Disagree } \\
\text { Strongly Disagree } \\
\text { Don't Know }\end{array}$ & $\begin{array}{r}20(10 \%) \\
65(45 \%) \\
94(45 \%) \\
30(14 \%) \\
0(0 \%)\end{array}$ & $\begin{array}{r}1(10 \%) \\
195(48 \%) \\
114(28 \%) \\
21(5 \%) \\
32(8 \%)\end{array}$ & $\begin{array}{c}55(9 \%) \\
247(39 \%) \\
176(28 \%) \\
28(4 \%) \\
320(20 \%)\end{array}$ \\
\hline \multicolumn{4}{|c|}{ Many rehabilitation professionals are uncomfortable with the idea of working with people living with HIV/AIDS** } \\
\hline $\begin{array}{l}\text { Strongly Agree } \\
\text { Agree } \\
\text { Disagree } \\
\text { Strongly Disagree } \\
\text { Don't Know }\end{array}$ & $\begin{array}{r}15(7 \%) \\
72(35 \%) \\
69(33 \%) \\
4(2 \%) \\
48(23 \%)\end{array}$ & $\begin{array}{l}29(7 \%) \\
167(41 \%) \\
121(30 \%) \\
11(3 \%) \\
75(19 \%)\end{array}$ & $\begin{array}{c}55(9 \%) \\
271(43 \%) \\
116(18 \%) \\
8(1 \%) \\
184(29 \%)\end{array}$ \\
\hline \multicolumn{4}{|c|}{ Serving people living with HIV is more demanding than serving clients with other chronic illnesses or conditions** } \\
\hline $\begin{array}{l}\text { Strongly Agree } \\
\text { Agree } \\
\text { Disagree } \\
\text { Strongly Disagree } \\
\text { Don't Know }\end{array}$ & $\begin{array}{l}28(14 \%) \\
68(33 \%) \\
82(39 \%) \\
13(6 \%) \\
17(8 \%)\end{array}$ & $\begin{array}{c}9(2 \%) \\
46(11 \%) \\
241(60 \%) \\
27(7 \%) \\
79(20 \%)\end{array}$ & $\begin{array}{c}18(3 \%) \\
72(11 \%) \\
253(40 \%) \\
26(4 \%) \\
264(42 \%)\end{array}$ \\
\hline \multicolumn{4}{|c|}{ I personally feel that rehabilitation for people living with HIV/AIDS should be a larger priority*** } \\
\hline $\begin{array}{l}\text { Strongly Agree } \\
\text { Agree } \\
\text { Disagree } \\
\text { Strongly Disagree } \\
\text { Don't Know }\end{array}$ & $\begin{array}{ll}51(25 \%) \\
120(58 \%) \\
15(7 \%) \\
4(2 \%) \\
17(8 \%)\end{array}$ & $\begin{array}{c}33(8 \%) \\
152(38 \%) \\
67(17 \%) \\
1(<1 \%) \\
147(37 \%)\end{array}$ & $\begin{array}{c}42(7 \%) \\
246(39 \%) \\
79(12 \%) \\
5(1 \%) \\
260(41 \%)\end{array}$ \\
\hline
\end{tabular}

Notes: * Table for rehabilitation professionals based on $N=1042$ as there were 16 non-responses on item that identified as served or not served. Percentages may not add to $100 \%$ due to rounding. ${ }^{* *}$ X2 significant at $p<.001$ 
12

HIV and Rehabilitation Training Needs

Worthington, O'Brien, Myers, Nixon, \& Cockerill

Journal of Research in Interprofessional Practice and Education

Vol. 4.1

June 2014

\section{Discussion}

This study was the first national survey to explore both HIV specialist and rehabilitation professionals' knowledge of and views about HIV rehabilitation in Canada. Despite the potential role for rehabilitation professionals in HIV care and treatment, only a minority currently serve people living with HIV in Canada [8]. Those who do serve very few people living with HIV. Furthermore, people living with HIV who are served by rehabilitation professionals are largely seen for rehabilitation issues unrelated to their HIV status [8]. In addition, very few HIV specialists are referring to rehabilitation professionals, which results in a gap between the needs of people living with HIV and rehabilitation services provided [9]. Reasons for this disparity may

reflect a complex set of personal (attitudinal and training) and healthcare system factors. Results from this survey explore knowledge and views on HIV rehabilitation among HIV specialists and rehabilitation professionals. These findings can be used to inform future training and mentorship priorities for health professionals to help address the gap between the disablement experiences of people living with HIV and the lack of rehabilitation service provision.

\section{Education and training needs}

Of the $61 \%$ of rehabilitation professionals who had never worked with people living with HIV, 27\% were unwilling to work with people living with HIV and $46 \%$ were unsure [8]. This unwillingness or uncertainty to serve people living with HIV may be due to a feeling of being unqualified or a discomfort working in a new field. This assumption is supported by our survey findings whereby $67 \%$ of rehabilitation professionals disagreed or strongly disagreed that rehabilitation professionals possess adequate knowledge and skills to assess and treat people living with HIV, and 91\% strongly agreed or agreed that rehabilitation professionals who provide services for people living with HIV need specialized training. Although having knowingly served an HIV-positive client was positively associated with higher reported HIV knowledge and receipt of specialty training or continuing education in HIV rehabilitation in the past 5 years [8], our findings suggest that learning needs exist among rehabilitation professionals, both those who have and have not served people living with HIV, as well as HIV specialists.

Only one-third of rehabilitation professionals who had served people living with HIV stated they received any training in HIV as part of their professional health degree, only slightly more than the $24 \%$ who received training and had not served people living with HIV, and more than the $14 \%$ of HIV specialists who stated they received training in rehabilitation as it relates to HIV as part of their professional degree. This lack of training may contribute to gaps in service provision, and it points to a need for HIV training and education among rehabilitation professionals and among HIV specialists. Despite the evidence that interaction with people living with HIV is important in reducing anxiety and increasing willingness to serve people living with HIV among rehabilitation professionals [16-18], less than $15 \%$ of the rehabilitation professional education received was in the form of HIV clinical internships and mentorship or shadowing opportunities with health professionals 
HIV and Rehabilitation Training Needs

Worthington, O'Brien, Myers, Nixon, \& Cockerill

Journal of Research in Interprofessional Practice and Education

Vol. 4.1

June 2014 in HIV care, and little specialty training or education involved mentorship or shadowing opportunities. These trends were similarly seen among HIV specialists, highlighting the role for practice-based education and mentorship opportunities in HIV and rehabilitation.

Respondents in this survey felt that a range of health professions, including their own, were important in the rehabilitation of people living with HIV, which reinforces the importance of interprofessional HIV care. Views around perceived knowledge, skills, comfort level, and training as they relate to HIV care were similar among the three participant groups, with more rehabilitation professionals who had not served people living with HIV reporting they "didn't know." Findings suggest that many HIV specialists and even more rehabilitation professionals do not believe that rehabilitation professionals possess adequate knowledge and skills to work in HIV care, and the majority of all three participant groups strongly agree that specialized training is needed to work in the field. With respondents feeling that rehabilitation in HIV should be a larger priority, our results support the need for further education and training opportunities in HIV care so that rehabilitation professionals may better and more confidently address the disablement needs of people living with HIV, and HIV specialists may feel confident referring their clients to rehabilitation services. Further education and training of health professionals as well as people living with HIV in HIV rehabilitation may help to a) increase information about the availability of resources, leading to HIV-positive patients asking their physicians for referrals to rehabilitation services, b) reduce stigma and discrimination among providers, and c) increase knowledge among health professionals about HIV.

\section{HIV mentorship and training programs}

Due to the complex nature of HIV disease, comprehensive rehabilitation care for people living with HIV requires a team approach, suggesting an interprofessional approach to training and mentorship will improve collaborative practice. By working together, health professionals get an understanding of others' scope of practice, learn how to collaborate, and make joint clinical decisions [13,19]. This approach offers the benefits of collaborative practice and addresses any discipline-specific needs that may arise throughout the learning process.

Several mentorship models have been implemented in the field of HIV in Canada. The Canadian HIV/AIDS Mentorship Program (CHAMP) is a peer education program developed to increase capacity among primary care physicians. Experienced HIV primary care physicians (mentors) are paired with physicians new to the field (mentees). Mentors provide resources on HIV care, help physicians remain up to date on treatment advances, and familiarize mentees with services and resources available to patients in their region [20]. This program evolved to form the Ontario Society of Physicians in HIV Care, which provides access to evidence-based information, continuing education, mentors, and peers to physicians in urban and rural Ontario [21]. Similar models exist with other professions such as the Canadian Association for Nurses in AIDS Care, which initiated a mentorship program in 1997 to create a network of nurses working in HIV care in Québec [22]. Evaluation of the program was 
14

HIV and Rehabilitation Training Needs

Worthington, O'Brien, Myers, Nixon, \& Cockerill

Journal of Research in Interprofessional Practice and Education

Vol. 4.1

June 2014 extremely positive, with $90 \%$ of mentors and novices stating they were satisfied with the mentorship process. Strengths included information-sharing between novices and other colleagues, development of problem-solving skills, and the ease of communication between mentor and novice [22]. More recently, a Canadian university implemented an elective in HIV care for undergraduate medical students comprised of lectures, small-group learning, and clinical and community placements. This studentled initiative was positively received, demonstrating increases in HIV knowledge among participants [23]. A similar model may be considered for other health professionals to increase knowledge and training in HIV care.

The Canadian Working Group on HIV and Rehabilitation (CWGHR) implemented a six-month interprofessional mentorship program in Ontario. This model builds on an interprofessional curriculum for rehabilitation professionals on HIV care previously developed by the CWGHR [24]. Mentors include people living with HIV and rehabilitation professionals who work in HIV care, and mentees include rehabilitation professionals who self-identified learning needs in HIV and rehabilitation [25]. The model includes a combination of structured problem-based learning sessions and informal open communication between mentors and mentees. Participants viewed this mentorship program positively for the ability to establish networks in HIV and rehabilitation and the ability to learn from mentors living with HIV. However, challenges to participation included scheduling, lack of support to devote time away from clinical responsibilities to participate in the program, and limited opportunities to implement new knowledge for mentees who did not commonly see HIV clients in their practice [25].

Another evolving mode of education and mentorship is via the Internet. Online education offers benefits of accessing information or course work asynchronously and may be an ideal model of education and mentorship for busy clinicians, or clinicians in rural regions. Online education and mentorship allows increased time for reflection and synthesis [26], can promote critical thinking and problem-solving in a collaborative environment [27], and can be equally effective as face-to-face learning [28]. In particular, e-learning with interactive video was associated with better learning performance compared with other non-interactive video, non-video, or traditional forms of classroom learning, highlighting ways to further adapt HIV and rehabilitation educational curricula [29]. The CWGHR developed an online course on HIV and rehabilitation as an evolution from their interprofessional inperson course. Course content is divided into eight modules, beginning with an introduction to HIV. Each module builds upon learning in the area of HIV as it relates to rehabilitation professionals in an interactive and engaging manner [30]. Most recently, CWGHR launched an E-Module for Evidence-Informed HIV Rehabilitation (e-module), an electronic resource that incorporates current best evidence on HIV and rehabilitation. Notable features of the e-module include chapters on aging, concurrent health conditions, cognitive rehabilitation, and six complex cases with guiding questions developed to facilitate learning through the integration and practical application of knowledge in clinical scenarios rehabilitation professionals may face in practice [31]. 
HIV and Rehabilitation Training Needs

Worthington, O'Brien, Myers, Nixon, \& Cockerill

Journal of Research in Interprofessional Practice and Education

Vol. 4.1

June 2014

\section{Recommendations for future HIV training and mentorship}

Given the exploration of the knowledge and views on HIV rehabilitation and emerging professional and service delivery issues among both HIV specialists and rehabilitation professionals in this national survey, we offer the following recommendations for future education and mentorship in HIV rehabilitation. First, people living with HIV should be an integral component to any mentorship or training model as educators and mentors to positively influence willingness of rehabilitation professionals to serve people living with HIV. Second, training and mentorship should be interprofessional in nature, including a range of health professionals such as rehabilitation professionals (e.g., OTs, PTs, SLPs) and referring health providers (e.g., physicians, nurses, social workers, pharmacists, dietitians, psychologists) in HIV care [24]. Further interprofessional links should be made with rehabilitation providers at community-based service organizations since these organizations often provide other non-traditional forms of rehabilitation (e.g., massage therapy), and because many health providers are already referring to these organizations to address social participation issues [9]. Third, education, training, and mentorship should be targeted at both current and future health professionals to maximize change in practice. This means including HIV rehabilitation content in pre-licensure training programs, as well as offering continuing education for clinicians already in practice. People living with HIV should be included in this HIV rehabilitation education and mentorship to increase their capacity to recognize the types of disability they may be facing and to enable discussion of their need for rehabilitation services with their health providers. Fourth, education and mentorship should be delivered in multiple forms (online, face-to-face, videoconference, etc.) to increase accessibility of training among professionals and people living with HIV who are living in rural and urban regions of Canada. Finally, although these recommendations are specific to the context of HIV and rehabilitation as explored in our study, given the forthcoming gaps in the capacity of the health environment to adequately care for people living with HIV [32], these recommendations for training and mentorship may be considered more broadly for other regulated health professionals with a role in the care and treatment of people living with HIV.

\section{Limitations}

This study was conducted with a random sample of rehabilitation professionals and the known population of HIV specialists working in Canada. We focused our analyses on rehabilitation and HIV health professionals and did not survey people living with HIV or other allied professionals (e.g., chiropractors, massage therapists, AIDS service organization counsellors) who may have a role in HIV rehabilitation. Future research may address rehabilitation in the context of HIV from the perspective of these other stakeholders. Although the overall response rate was good for rehabilitation professionals (74\%) and slightly less but still acceptable for HIV specialists (63\%), the ineligibles and refusals depleted the number of the successfully completed questionnaires for rehabilitation professionals and HIV specialists to $53 \%$ and $29 \%$ of our samples, respectively. Furthermore, due to small sample size, we 
16

HIV and Rehabilitation Training Needs

Worthington, O'Brien, Myers, Nixon, \& Cockerill

Journal of Research in Interprofessional Practice and Education

Vol. 4.1

June 2014 were unable to statistically determine similarities and differences between the HIV specialist groups. Nevertheless, this is the first survey on HIV rehabilitation administered to both rehabilitation professionals and referring HIV specialists to explore ways to better enhance HIV rehabilitation for people living with HIV.

\section{Conclusions}

Despite the potential role rehabilitation professionals play in HIV care and treatment, only a minority currently serve people living with HIV in Canada. Rehabilitation professionals and HIV specialists possess varying knowledge of and views on HIV/AIDS rehabilitation. Findings indicate the need for further interprofessional education, training, and mentorship of health professionals to address the gap between the disablement needs of people living with HIV and lack of rehabilitation service provision.

\section{References}

1. Hoy-Ellis, C.P., \& Fredriksen-Goldsen, K.I. (2007). Is AIDS chronic or terminal? The perceptions of persons living with AIDS and their informal support partners. AIDS Care, 19, 835-843.

2. Bhaskaran, K., Hamouda, O., Sannes, M., Boufassa, F., JohnsonHoy-Ellis, C.P., \& FredriksenGoldsen, K.I. (2007). Is AIDS chronic or terminal? The perceptions of persons living with AIDS and their informal support partners. AIDS Care, 19, 835-843.

3. Rusch, M., Nixon, S., Schilder, A., Braitstein, P., Chan, K., \& Hogg, R.S. (2004). Impairments, activity limitations and participation restrictions: Prevalence and associations among persons living with HIV/AIDS in British Columbia. Health Qual Life Outcomes, 2, 46.

4. O’Brien, K.K., Bayoumi, A.M., Strike, C., Young, N.L., \& Davis, A.M. (2008). Exploring disability from the perspective of adults living with HIV/AIDS: Development of a conceptual framework. Health Qual Life Outcomes, 6, 76.

5. Liu, C., Ostrow, D., Detels, R., Hu, Z., Johnson, L., Kingsley, L., \& Jacobson, L.P. (2006). Impacts of HIV infection and HAART use on quality of life. Quality of Life Research, 15, 941-949.

6. Worthington, C., Myers, T., O’Brien, K., Nixon, S., Cockerill, R. (2005). Rehabilitation in HIV/AIDS: development of an expanded conceptual framework. AIDS Patient Care STDS, 19, 258-271.

7. United Nations Economic and Social Commission for Asia and the Pacific (UNESCAP). (2003). Understanding community based rehabilitation. Bangkok: United_Nations_Economic and_Social. _Commission for_Asia and_the _Pacific_(UNESCAP). URL: 'thttp:_/_wwww.unescap_org/esid/psisí

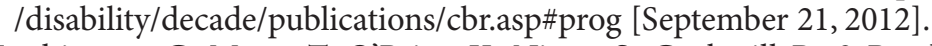

8. Worthington, C., Myers, T., O’Brien, K., Nixon, S., Cockerill, R., \& Bereket, T. (2008). Rehabilitation professionals and human immunodeficiency virus care: results of a national Canadian survey. Archives of Physical Medicine and Rehabilitation, 89,105-113.

9. Worthington, C., O’Brien, K., Myers, T., Nixon, S., Cockerill, R. (2009). Expanding the lens of HIV services provision in Canada: results of a national survey of HIV health professionals. AIDS Care, 21, 1371-1380.

10. May, K.M., Meleis, A.I., \& Winstead-Fry, P. (1982). Mentorship for scholarliness: Opportunities and dilemmas. Nursing Outlook, 30, 22-28.

11. Cotter, J.J., Coogle, C.L., Parham, I.A., Head, C., Fulton, L., et al. (2004). Designing a multi-disciplinary geriatrics health professional mentoring program. Educational Gerontology, 30, 107-117.

12. Pololi, L., \& Knight, S. (2005). Mentoring faculty in academic medicine. A new paradigm? Journal of General Internal Medicine, 20, 866-870.

13. O’Brien, K., Bone, G., Zack, E., \& Solomon, P. (2008). HIV and rehabilitation: Development of a conceptual framework for curriculum planning. International Journal of Rehabilitation Research, 31, 189-197.

14. World Health Qrganization (2001). Internationalclassification of functioning, disability and health

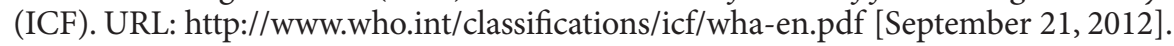

15. Dillman, D. (2000). Mail and internet surveys: The tailored design method. New York: John Wiley \& Sons. 
17

HIV and Rehabilitation Training Needs

Worthington, O'Brien, Myers, Nixon, \& Cockerill
16. Pucktree, T., Kasiram, R., Moodley, M., Singh, R.M., \& Lin, J. (2002). Physiotherapists and human immunodeficiency virus/acquired immune deficiency syndrome: Knowledge and prevention: A study in Durban, South Africa. International Journal of Rehabilitation Research, 25, 231-234.

17. All, A.C., \& Fried, J.H. (1996). Factors influencing anxiety concerning HIV/AIDS in rehabilitation workers. Journal of Rehabilitation, 63, 45-51.

18. Samuel, J.C., \& Boyle, M. (1989). AIDS training and social services. AIDS Care, 1, 287-296.

19. Solomon, P., Salvatori, P., \& Guenter, D. (2003). An interprofessional problem-based learning course on rehabilitation issues in HIV. Medical Teacher, 25, 408-413.

20. Klein, A., Rachlis, A., Peter, A., Throop, R., \& Hettiarchchi, D. (1996). The Canadian HIV/AIDS mentorship program (CHAMP): A peer education model_for_HIV_primary_care_International.

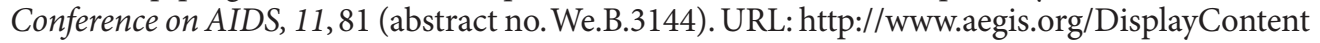
1/? SectionID=301013'! September 21, 2012].

21. Ontario HIV Treatment Network. (2005). Advancing HIV Policy and practice_through a_network of, excellence_Qntario HIV Treatment_Network strategic plan to 2010. URL:htttp://wwww_ohtn.on.ca.' '/Documents/Publiçations/OHTN_Strat_0505.pdf́,'[September 21, 2012].

22. Paquin, M.J., \& Lambert, A. (2000). The collaborative project: An effective Canadian partnership in HIV/AIDS nursing care. JANAC: Journal of the Association of Nurses in AIDS Care, 11, 57-64.

23. Chew, D., Jaworsky, D., Thorne, J., Ho, M., Andany, N., Morin, C., Hoffman, N., Henshaw, C., Rourke, S.B., Fisher, M., \& Rashlis, A. (2012). Development, implementation, and evaluation of a student-initiated undergraduate medical education elective in HIV care. Medical Teacher, 34(5), 398-403.

24. O’Brien, K., Bone, G., Sinclair, L., \& Solomon, P. (2010). Rehabilitation in the context of HIV: An interprofessional multi-stakeholder process for curriculum development. Journal of Allied Health, 39, 131-137.

25. Solomon, P., O’Brien, K., Hard, J., Worthington, C., \& Zack, E. (2011). An HIV mentorship program for rehabilitation professionals: Lessons learned from a pilot initiative. International Journal of Therapy and Rehabilitation, 18, 280-289.

26. O’Brien, B.S., \& Renner, A.L. (1998). Opening minds. Values clarification via electronic meetings. Computers in Nursing, 16, 266-271; Quiz, 273-264.

27. Sternberger, C.S. (2002). Embedding a pedagogical model in the design of an online course. Journal of Nursing Education, 27, 170-173.

28. Neuhauser, C. (2002). Learning style and effectiveness of online and face-to-face instruction. American Journal of Distance Education, 16, 99-113.

29. Zhang, D., Zhou, L., Briggs, R.O., \& Nunamaker, J.F. (2006). Instructional video in e-learning: assessing the impact of interactive video on learning effectiveness. Information \& Management, $42,15-27$.

30. Canadian Working Group_on HIV and_Behabilitation.(2010). Rehabilitation in the context of HIV:

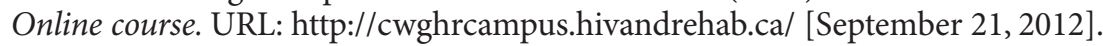

31. Canadian Working Group_on HIY_and Rehabilitation. (2011)_E-Module_for evidence informed_HIV,

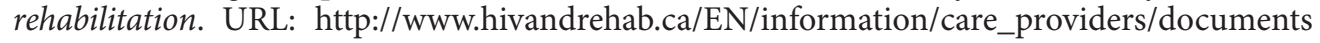
ICWGGHR E-moduleEvidence-InformedHIVRehabilitationfinal.pdf!' [September 21, 2012]. 